Proc. Estonian Acad. Sci. Eng., 2002, 8, 1, 18-37

\title{
On technical management of large power transmission networks
}

\author{
Taivo Kangilaski \\ IT Division, Eesti Energia Ltd, Laki 24, 12915 Tallinn, Estonia; Taivo.Kangilaski@energia.ee \\ Received 15 June 2001, in revised form 7 November 2001 \\ Abstract. This article considers problems which arise by technical management of large \\ transmission networks and describes a technical software-related management system "Event \\ Navigator", developed at Eesti Energia AS.
}

Key words: transmission network, technical management, software.

\section{INTRODUCTION}

The larger the network the more elements it contains and the more persons and companies are involved in its operation. Such an intricate organizational structure may be changed quite often.

Coordination of the functioning of a network requires inputs and decisions from a number of specialists, because for the alignment or repair of a network element often other elements must be switched off. An optimal work plan should be developed, based on two important criteria. Firstly, a safe network operating regime must be guaranteed, minimizing network downtime for customers. Secondly, maintenance works should be performed as regularly as possible and the occurrence of faults should be minimized.

Worldwide, this field is covered by Supervisory Control And Data Acquisition software (SCADA) $\left[{ }^{1-7}\right]$ and by Geographic Information Systems (GIS) software $\left[{ }^{8-10}\right]$.

Based on detailed analysis of Harris SCADA product XA/21 [ $\left.{ }^{11}\right]$, ABB SCADA product S.P.I.D.E.R. $\left[{ }^{12}\right]$, IVO SCADA system $\left[{ }^{13}\right]$, Siemens SCADA product SINAUT-SPECTRUM $\left[{ }^{14,15}\right]$, and TEKLA Corporation GIS product Xpower $\left[{ }^{16,17}\right]$, we identified main domains of the management systems and their functions. All the investigated systems had very powerful user interface, oriented 
mainly to dispatcher's use, but coordination of maintenance works appeared weak and powerful workstations were needed for users.

Our goal was to create an integrated software for handling the subsystems and their functions required by the technical management of transmission networks. The article is organized as follows. Firstly, we define the domains of the network that should be covered by technical management $\left[{ }^{1-8}\right]$. Secondly, we describe the functions of these domains and, finally, we offer the principles for compiling hardware configurations and for designing the software. Hardware configuration principles and software elaboration have been studied by the authors of SCADA and GIS and is described in $\left.{ }^{[18-27}\right]$.

We discuss these issues in the context of Eesti Energia's (EE) management system Event Navigator (ENav), that functions in Web-based Oracle environment. The main user of ENav is the National Grid and its Dispatch Centre. Narva power plants (Balti PP, Eesti PP), Iru PP, Televõrk Ltd., Siemens Electroservices, etc., use this system to manage the National Grid facilities. Today ENav has more than 450 registered users.

\section{SUBSYSTEMS OF THE NETWORK MANAGEMENT SYSTEM}

In order to create an integrated computer-based network management software for technical management of a large transmission network, we must determine its subsystems. Thus, we analysed the process of EE electricity and telecommunication technical management. The majority of information was taken from tender documents to the EE Dispatch Centre SCADA $\left[{ }^{11-15}\right]$. In addition, the EE National Grid GIS system, which uses Xpower $\left[{ }^{17}\right]$, was taken into account. Information related to the subject is described also in $\left.{ }^{28-33}\right]$, because we could handle this subject also as a workflow management.

As a result, in ENav we distinguish the following domains.

\subsection{Management of the process as a whole}

The term process is used to refer to the chain of events ranging from detecting a defect or downtime of a network element or to the elimination and analysis of the latter or to the following use of data obtained from the analysis concerning the planning of preventive maintenance. In terms of software, differentiation is made between network elements and the personnel engaged in network operations $\left[{ }^{3,18}\right]$.

\subsubsection{Network approach}

The process is described through events. An event is a situation which has taken place and has been registered. Each event is connected to some network element or groups of elements. A network element can be a device or building, land area, etc., which supports network operations. In power industry, we may divide network elements into the following groups: 
- thermal, thermal-protective, relay-protective and substation facilities;

- transmission lines and conduits (power transmission lines, telecommunication channels, etc.);

- telecommunication facilities;

- measuring instruments and telemeasurements (measuring points, meters, etc.);

- buildings;

- other (geographical elements such as rivers, trenches, crossings).

This is the list that ENav uses today. However, it can be simply modified upon request (registered immovables, transmission line crossings with rivers, roads, etc.). Our objective is to record the events in as much details as possible to enable us to use the analysis results in planning. The event is described as follows:

- the transition of the network element from one state to another;

- event type (failure, defect, switch-off, works, reserve);

- connections with other network elements;

- its geographical location;

- its character (emergency, planned, non-planned);

- reasons that triggered it;

- its desired, planned, or actual time;

- related persons;

- related documents;

- additional information in the form of free explanatory text.

We are designing an expert system comprising a training simulator that will allow to model events and offer solutions in real time, depending on the situation.

When we analysed telecommunication and electricity network topology, we found that all events were related to data that describe the network elements. To obtain a detailed overview of the event we should take a close look at the data groups needed to describe a network element. For example, inside ENav, for electricity and telecommunications network we have the following data groups:

- the network element itself;

- horizontal and vertical interconnections (logical and physical interconnections together);

- measurements (energy, voltage, temperature, etc.);

- dynamically created or updated network element description fields;

- documentation, events, companies and personnel data (persons with operational rights, organizers of operations, work performers, owner information, service user information) related to the network element;

- reasons for overhaul;

- damage, downtime and fault reasons and neural network memory matrices for fault prediction and for short-time consumption forecast.

This sample of data groups has proved sufficient to describe elements of the electricity network and telecommunication network elements in our network management software.

In ENav, the integrated measuring data are being received every five minutes from the EE Dispatch Centre SCADA RTUs (Remote Terminal Units) and 
commercial measurements (energy) once per hour from CENTRAPULS terminals. In ENav, we obtained over 4000 measurements.

\subsubsection{User approach}

As explained above, processes are described through events. However, in order to manage the process, we need also persons or robots. For that reason we developed a three-dimensional management structure that corresponds to the operational management structure required for the operation of a network element.

First dimension - the node level (Fig. 1a). Node is a functional unit, department, or the whole company. At this level of abstraction, we can describe the process of event coordination and define connections between nodes. We can use this method to describe a mesh structure of nodes.

Second dimension - the layer level (Fig. 1b). Layer is a structural element of a node. It may be a functional unit, department, or the whole company. Each node consists of at least one layer. We can describe the layers only using a tree-type hierarchy - it means that every node has only one top layer.

Third dimension - the workplace level (Fig. 1c). Workplace is a structural element of a layer. Workplace is a body of functional activities, located at the node level and applicable to the users working at this workplace. Each layer should have at least one workplace. All workplaces are attributed to a type and each type has some assigned functions.

In general, the following default workplace types can be used:

- rank and file (RF, responsible for primary event processing and analysing);

- decision-maker (DM, responsible for triggering the event);

- dispatcher (DP, responsible for working permissions and reduction facilities for maintenance and return to the operation);

- observer (can only observe).

Since large networks have often a sophisticated structure, the network administrator must be able to create new workplace types and change their functions. This will improve system surveillance. Since there exist many different functions, one may want to reduce the number of workplace types that result from

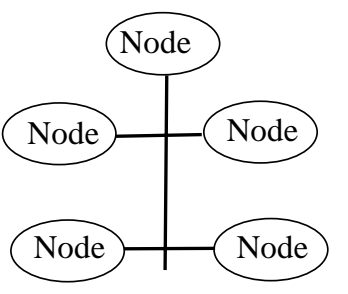

(a)

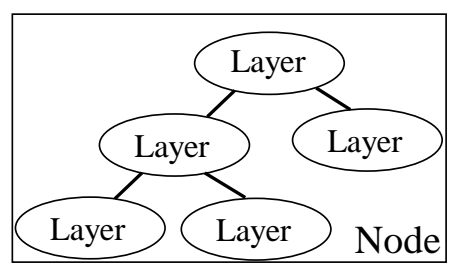

(b)

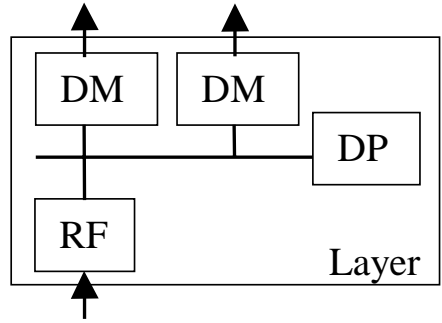

(c)

Fig. 1. Three-dimensional management structure: (a) node level; (b) layer level; (c) workplace level. 
these functions, by applying the following definitions of the systems: 1) assigned to the user, 2) assigned to the node, and 3) assigned to the workplace type. The groups exclude each other and are ranked according to priority. This means that if the user has been assigned some functions, then the functions assigned to the node or workplace type, etc., are disregarded.

\subsubsection{Merging the network and user approaches}

The management system becomes a whole when we connect user-based and network-based approaches into an integrated whole. For that purpose, we developed the term relevance. Relevance is the ability of a network element to create connections to the relevant layers and nodes. Through the element relevance it is possible to describe the specific operational control structure for each individual network element.

We developed the following functional properties of relevance, based on the operational aspect:

- operational knowledge (supreme decision-making level);

- operational control (dispatch control of the network elements);

- operational maintenance (direct performer of switching);

- informative knowledge (obligation to report the operations ongoing or planned in the network element);

- administration (engineering and technical personnel responsible for the network element);

- maintenance (maintenance personnel responsible for the network element);

- owner (to show the network element owner);

-e-messages (to inform by e-mail or sms-message about the ongoing processes);

- service consumer (end user who consumes the service).

If we assign relevances to node layers only, the presented events move to the respective node level and move on within the levels, taking into account the relevance and interlevel hierarchy. An event exits the node always through the highest layer workplace that has the respective function. If no relevance has been described for the node levels, the events, in their chain of movement, enter the first workplace of the highest level where the user will define the next move of the event. Software users determine the relevance of all the facilities.

\subsection{Information exchange with other information systems}

A significant property of the network management system is the ability to create an interface for information exchange with other information systems that may be located in other network domains. That is important for integration with existing software which helps to guarantee the integral informational completeness of management systems $\left[{ }^{34}\right]$.

In ENav, we consider two types of interfaces: built-in interfaces (a part of software that is coded into the text of software and can be changed only by a 
programmer) and administrator-designed interfaces (the interfaces that administrators themselves can design using software components).

The built-in interfaces are used to have interface with a concrete information system. In ENav, we have interfaces with the following (Fig. 2): Oracle Financial, SCADA's telemeasuring part in the Central Control of the National Grid, the public information system running in Lotus Notes, the mode calculation software Power System Simulator for Engineering (PSS/E) $\left.{ }^{35}\right]$, working environment for users who have no access to EE's Intranet (based on e-mail), and request engines (based on e-mail).

The administrator-designed interfaces that are based on e-mail interface make it possible for the administrator to create e-mail forms within the limits defined by the keywords that the system recognizes and to which the system can automatically answer. In this way, the coordination of events has been implemented in EE, with regard to the downtime of such facilities which, as a rule, are under the operational control of the Baltics Dispatch Centre (DC) Baltija and/or require DC Baltija to be informed. In ENav, we can convert information to the Microsoft Excel format and create queries through Open DataBase Connectivity (ODBC) protocol.

\subsection{Focus on the company}

Each company and its subunits have the data that they want to share and the data that they want to keep in-house. In terms of making data in a large enterprise more company-focused, we differentiate three grades: 1) element information (access to information is defined by its relevance), 2) data describing the element (defined by server and/or database where they are located; each database may have its own description of an element), and 3) connections with other databases (in case we have a multiserver or multidatabase system, it is possible to detach oneself by cutting the logical connection with other databases). Selective display of information is important because we do not want to burden other users of the system with noise.

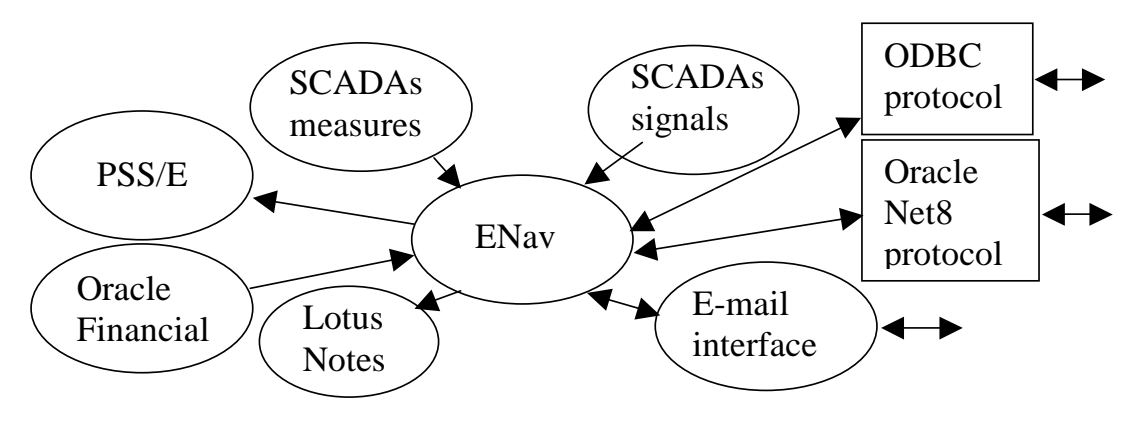

Fig. 2. Information exchange in the ENav. 


\subsection{Cooperation with company's subunits}

When running networks we have to do with many subunits. Network element operations are often related to their most different combinations. Therefore, in order to operate efficiently, each structural unit must have an overview of the network elements in its area, of their descriptive data, current state and planned works $\left[{ }^{36,37}\right]$. All works require coordination with all parties in terms of regime, safety, and optimization. This approach allows us to minimize the downtime of the network elements and to find more effective solutions.

\subsection{Adaptability to company's changing structure}

In the management of a network it is only natural that its management and control structures change in time - new network elements, new managers, and operators appear, the company undergoes reorganization, etc. For this reason, it should be possible to describe different control structures. Using the mesh and tree structures together with network element relevance we have been able to describe any company structure. Based on design, databases should proceed from the principle that network elements of the largest companies are located in different databases which, in turn, can be located in different database servers. This concept enables us to work as one system, but when a company wants to detach itself, it can work also in an autonomous mode. Thus the whole system works as a set of many autonomous cooperating systems (see Section 4).

\subsection{Administration of an unlimited number of users}

Network management systems should be designed so that a large number of users would not slow down the working speed of the software. The limiting characteristics of most of the systems are: database inquiries are slow, resource usage of a server approaches an emergency limit, etc. In order to avoid getting stuck in the server's hardware resources (potential and capacity), we developed a data distribution subsystem for the network management system, which allows us to spread data between different databases, database servers, and Web servers (see Section 4). Another possibility to avoid these constraints is to use clustering ideology $\left[{ }^{38,39}\right]$.

\subsection{Report generation}

In general, the network management system should have a well-designed reporting and analysing logic or have an interface to such a system $\left[{ }^{40}\right]$. In our system, the user can combine the data, specify and apply it to standard reports which exist for various events. The user has a possibility to convert these reports at the workplace, so that the lists can be updated in real time. Our system has an interface with Microsoft Excel. 


\subsection{Compliance with the work of the dispatcher}

In general, operational work requirements can be reduced to the following: input data cannot be changed later, the person who made the entry is identifiable and so will be the time and location of the event. From these data we can determine later what happened, how the dispatcher behaved, how the incident was solved, etc. In the power system, dispatchers have special operational requirements, such as keeping an operational diary, working permissions for technical safety (provision is made for the dispatcher not to permit a repair group to the facility before acceptance of all working permits, and not to switch the network element back to work before closing all the work permits), keeping correct data, safe data maintenance, and archiving. These requirements have been included in ENav (see Section 3). Physical switching is performed through the dispatcher by the SCADA.

It is possible that in the course of time the domain of operation expands. It means that software should take this into account $\left[{ }^{40}\right]$.

\section{NETWORK MANAGEMENT}

Our research shows that network handling software should cover the following basic functions $\left[{ }^{41-45}\right]$.

Annual service and working plan composition and monitoring. Annual service and working schedules are used for planning work for the next financial year. The plans, drawn for one, three, and five years, help network managers to analyse budget implementation and progress. A plan passes four stages: 1) composing (automatic, according to the maintenance regulations of the network elements and manual elaboration according to the requests of the network element manager), 2) coordination, 3) approval by the respective control levels, and 4) performance monitoring. All the plans are composed automatically. Five months prior to the end of the financial year the software module is activated and an annual plan is generated. In the process of automatic generation, the software tries to minimize the system downtime and maximize intervals between new planned works, taking into account also the events included manually by the users. After the plan has been created, it is displayed to all the users engaged in the network element management, who can modify the plan if they wish so. After the plan has been completed in terms of its performers, the plan is coordinated within the entire power system. After coordination, the plan is approved and the monitoring of its implementation may start. The annual plan is not checked in terms of operational mode.

Monthly service and working plan composing and monitoring. A monthly service and working plan is produced to create an overview of works to be done and to check these plans by an operational mode. The initial monthly working plan is created by the software (afterwards it is fully manual) from the elements of the accepted annual plan. After that the operator can correct the plan and, if needed, 
add non-planned events. After the plan has been coordinated, the respective management levels will approve it. That enables monitoring of its implementation. If an element of the annual plan has become an element of the monthly plan, it can, nevertheless, be monitored through the annual plan as well (see Fig. 3). When the monthly service and working plan is completely approved, the plan will not be subject to any changes and corrections. If the situation changes, the works in the plan can be cancelled by the operator.

Budget planning and monitoring. The function of budget planning has been included in the task because overhaul work plans must be based on the existing financial resources. In ENav, we have interface with the financial accounting system Oracle Financial used in EE, but the system enables us to describe various financial accounting systems.

Administration of defects/faults. Defect administration implies a detected network element defect or fault during the inspection of the network element that does not affect the safety of its functioning (Fig. 4). So by the defect/fault administration, a faulty network element and the character and origin of its defect are identified and the detection time is recorded. The defect is thus stored as an event. Further, one can begin organizing the correction of the defect.

Depending on the criticality of the defect, the request for the removal of the defect may be submitted as an element of the annual or monthly plan, as a nonplanned or emergency overhaul application. After recording the defect, it is possible to observe the defect correction process as well as the defects not yet removed. An interface for a portable computer is being developed, which the staff that perform inspections of substations and lines can carry along to record all the defects immediately.

Switch-off account management. The accounting of switched-off network elements is aimed at several objectives. By counting switch-offs, we can predict the reliability of network elements and accommodate planned works. For instance, if circuit breakers are involved, it is defined how many switchings can be performed under rated current and short-circuit current before a major overhaul is required without delay. Moreover, in the case of a failure, one needs an analysis of what happened - which protections were applied, what had switched off what, etc. Thus, specialists can conduct an in-depth analysis of the problem and take measures. All switch-offs are being tied to events because they describe the course of the events.

In case a recorded event describes switch-offs, this event may serve as a basis for an application for planned works on a given device (to be included in the annual or monthly plan), or it may be submitted as an emergency event to dispatchers (Fig. 4).

Accounting of stand-by facilities. From the operational point of view, it is most important to have also a real-time overview of the facilities currently in reserve, since this information is instrumental with regard to ensuring the reliability of operation of the power network. Thus, a system has been introduced for accounting stand-by facilities. When a facility is transferred to the stand-by 


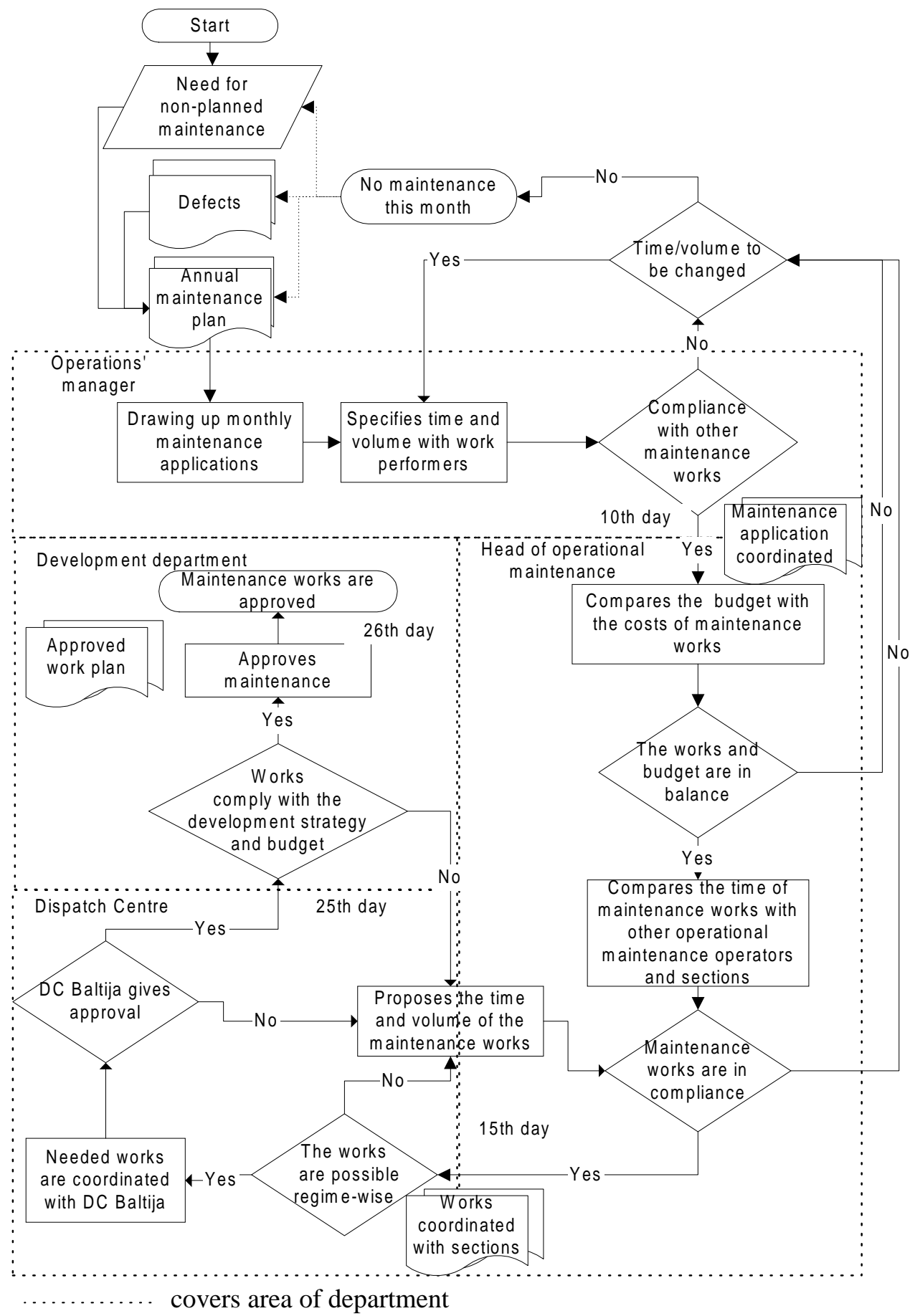

Fig. 3. Composition of a monthly service and working plan. 


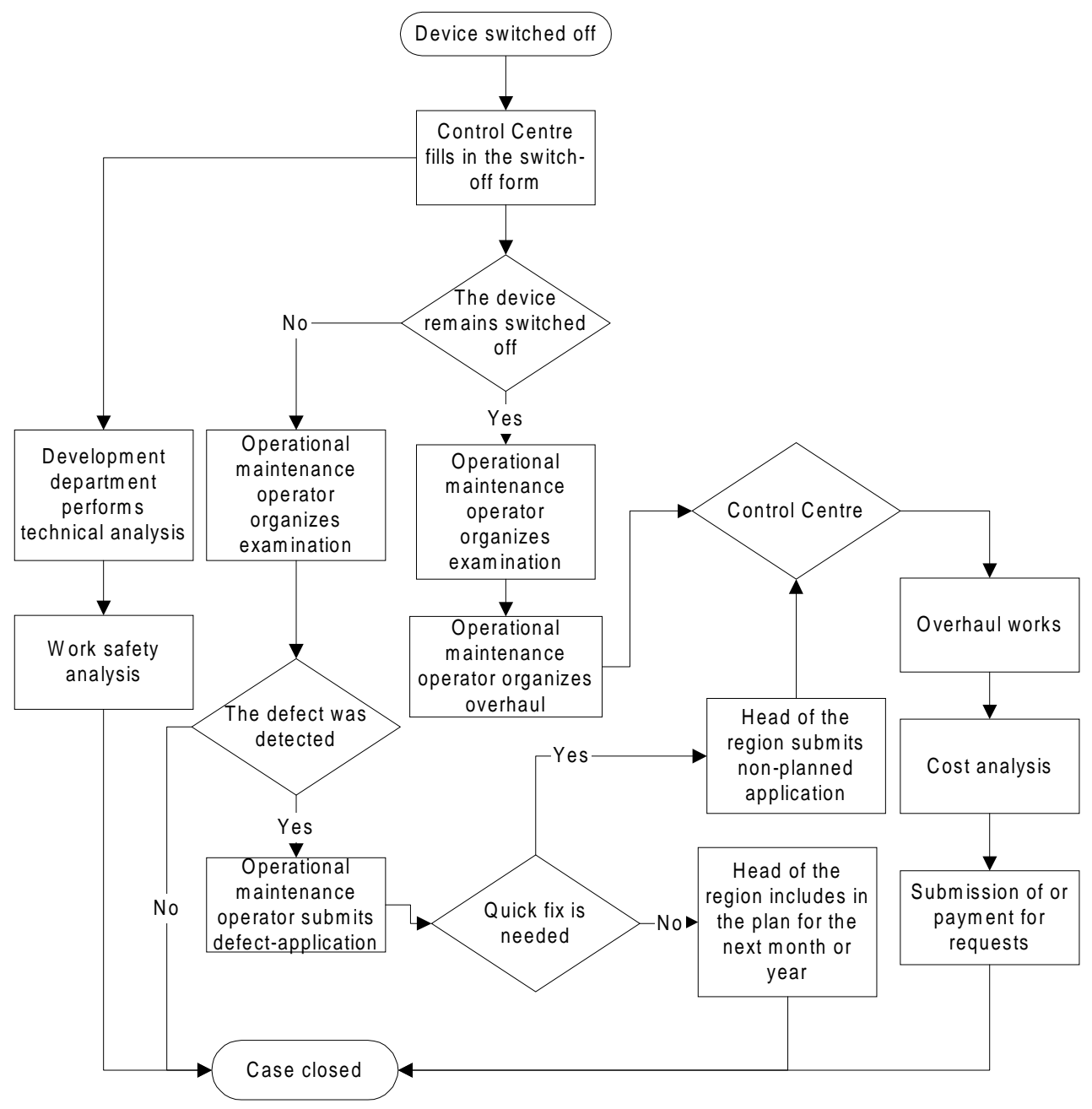

Fig. 4. Defect/fault management

status, the dispatcher creates a respective event. The event is closed after the facility has started to operate.

Recording, monitoring, and administering other events. Since large networks are sophisticated, they have properties that emerge and can be defined over a longer period of operation. ENav is a tool that allows the administrator to create new types of events, for example Substation Event and Investment Target. The administrator of the task can define the content of these events and the functionality for each type of an event - an emergency event, planned event, or a fact.

Overhaul applications. Overhaul applications are documents drawn up in order to receive a permit to perform the requested maintenance work on a network 
element. Planned overhaul applications are compiled manually, based on the monthly plan, and the element of the monthly plan is presented as an application. In case all the coordinated deadlines remain valid in the planned application, no intermediate coordination is required, and the application is immediately submitted to the person of highest authority to approve it. This person will decide whether to give or not to give a permission to start work.

Non-planned work applications are presented as overhaul-applications and are indicated as an event of emergency (malfunction). After the non-planned application has been coordinated and approved by the respective management levels, monitoring and management by the dispatcher starts. In case of emergency, the event becomes a subject of monitoring and supervision of the dispatcher immediately. All persons who are engaged in running of the network element can continuously observe the implementation process. In case the planned work was not finished on time, an application for the extension of the works can be submitted for coordination. This application passes the same chain of coordination as the initial overhaul-application did - it is coordinated with all the parties, the relevant levels of management have to approve it. If the decision is positive, it is transferred under dispatcher's monitoring and supervision (Fig. 5).

Accounting of working permissions for technical safety. Working permission is a document issued by the dispatcher to the on-site operator. Based on that permission, the operator prepares a workplace for the overhaul team. No nonemergency work can be performed without such permission. After the overhaul team has completed the work and removed all the unnecessary devices from the vicinity, the on-site operator notifies the dispatcher. Only after the dispatcher has closed the working permission, the dispatcher can close the event and return the network element to operation. By issuing the working permissions, the names of the permission issuer and recipient as well as the exact time of the issuing are recorded. The user can approach events through working permissions as well. One event may involve more than one permission. The working permission is a document on the basis of which a person can be held liable for an accident.

Monitoring of events by interest groups. An event may interest various groups - transmission line operators, transformer operators, relay protection staff, people in the development department, etc. In order to accommodate various interest groups, an analysing tool has been created. By means of this tool, the user can select information to be entered in the printout templates and generate various printouts. Thus the tool allows the user to sort data on the basis of restrictions defined by the user.

Dispatcher's logbook (operational diary). The logbook is designed for the communication dispatcher. Since dispatchers are often overloaded and engaged in phone calls, they may find it convenient to forward operational information also by electronic means. Then the information can be read and used immediately. The logbook also automatically registers the dispatcher's actions. Dispatcher's logbook displays all the events related to network elements, which are relevant for the given dispatcher. 


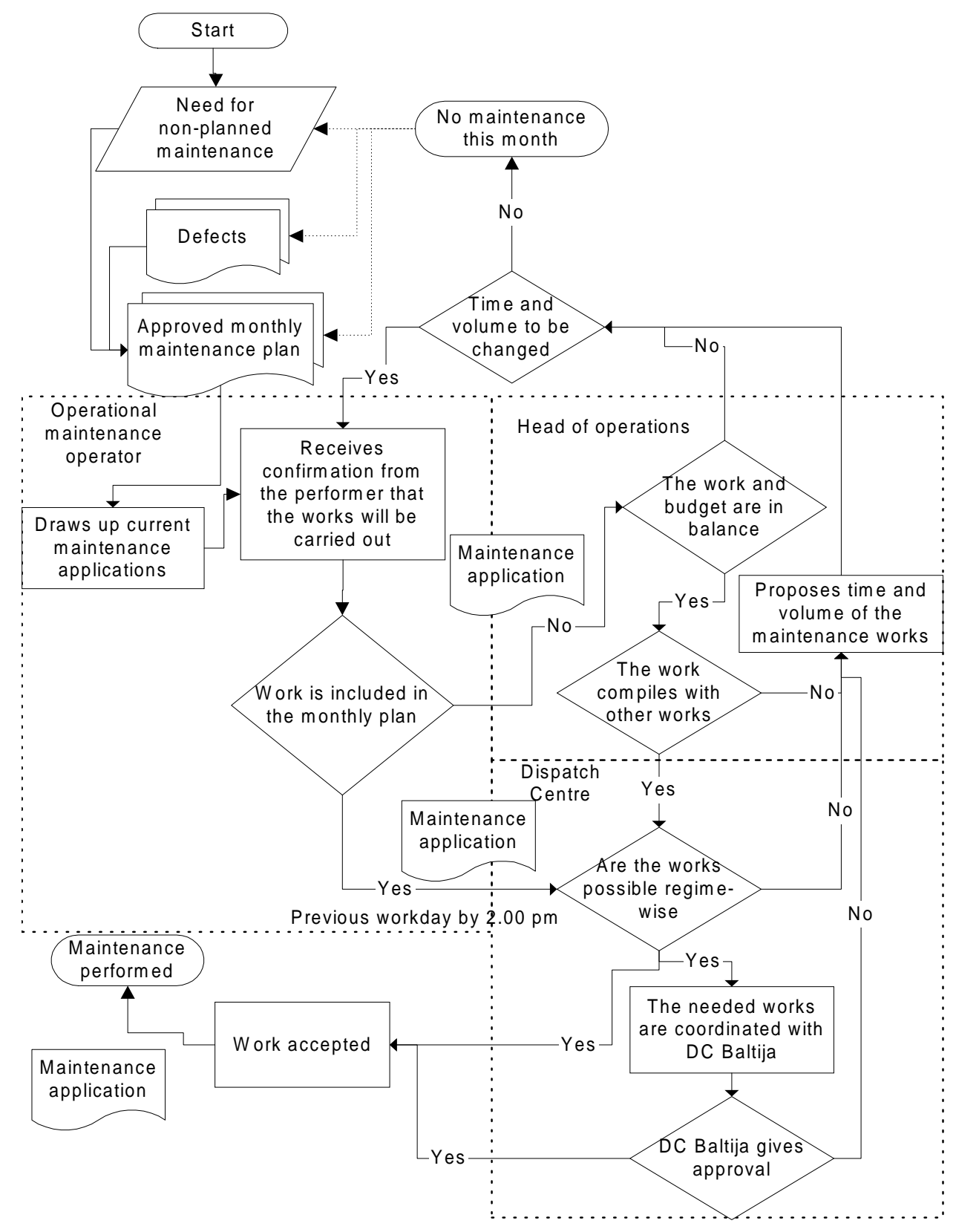

covers area of the department

Fig. 5. Management of the maintenance request. 
Maintenance of technical documentation. For planning, performing, and monitoring, it is important to manage the entire technical documentation. ENav document management is based on distributed data. That is, documents can be located anywhere as long as they are accessible via the Internet. The database contains a description of the access path to these documents. The documents can be linked to all network elements and element groups as well as element types and defined classes. By defining the documents, class and type definitions can be combined.

Printout generation system. Printout generation and development of new functions based on the printouts help the user to monitor the system better. Users can apply their own data to the existing printout frames and produce different views. The user can add the views to the functional properties of the workplace, thus making them variable in time. The administrator of the task can do the same and design different views for different users and workplace types to be included in the standard functions. Along with the functions developed by the administrator, built-in-system functions, that the administrator can select, are built by defining the corresponding data (for example, event creation forms, functions, design).

Inventory system. The inventory system is based on the same principles as the description of network elements. The inventory can be described as a group of functional elements of a network, composed of network elements. Each network element is described by the administrator, and access to the element components can be defined depending on the user. The inventory can be described in this way both by facility and by descriptive parameters and all the functions described in the part "Printout generation system" can be applied. When a facility is transferred from the inventory to the network, the pathway of the element is recorded, as is done with all other facilities.

Archiving history of the network element. In large systems it is quite common that over its lifetime, a network element is located in various network nodes and linked to various facilities. ENav has a function that provides an overview of the entire history of the device within the given network. On transferring the network element from one location to another, all links are archived. In addition, all former plans, events, and documents that are relevant remain linked to the network element and its former location.

Messenger system. The messenger's function is to give selected people selected information. For this purpose, the software has a module whereby the user can send a message to the workplaces selected by the user. Upon arrival, the message is immediately displayed on the interface of the Web workplace of the respective user. The objective was not to create a new complicated mailbox system but to improve the efficiency of human communication within the software. The other message system of the software is a reminder/notification system based on e-mail. The system is designed to notify users about the information that has arrived in the waiting list for their processing, such as events, network element downtime applications, shutdowns, overhaul completion, annual/monthly maintenance plan 
closing, etc. Messages can be forwarded to a mobile network or pagers as sms-messages, depending on the service provider.

Multilingual support. ENav allows use of several languages, because the task may involve people whose native tongue is different from the languages used in the system. Today we have user interfaces in Estonian and Russian. The code table of the database is UFT-8, where some characters are described as 2- or 3-byte symbols.

Monitoring loading orders of a power plant. The management of the loading orders of power plants (in our case, Balti PP, Eesti PP, and Iru PP) is important for Central Control dispatchers. Therefore all loading orders are recorded as events. With a new order, the software closes the previous order. Valid orders are displayed also in the operational diary and as individual views.

Fault projections. A fault projection mechanism is necessary to improve network administration planning. If we prevent the failure, a significant saving of financial resources results. Fault projections are instrumental in drawing up optimal downtime and investment plans. To predict faults we use a feed-forward neural network $\left[{ }^{46}\right]$.

Short-time forecast of electric power consumption. Dispatchers need consumption projections in order to be able to plan regimes. The function "shortterm consumption projection (1-8 days)" can project various electric power consumption modes. The input data for consumption projection are composed of statistical consumption data, environmental air temperature, and light intensity.

Every projected hour was supplied with a feed-forward neural network of its own, i.e., we developed separate neural networks for all the respective hours of 1-8 days of projected consumption. The established projection error for 1-4 days was $\pm 3 \%$ and for $5-8$ days $\pm 6 \%$.

ENav data protection. Data protection plays an important role in software applications. Data may perish due to a human error, technical malfunction, intended theft, or damaging of information. Our network management software takes all these possibilities into account. Roughly, data protection can be divided into three classes: protection inside the software, protection defined by the environment, and administrative protection.

The following data protection measures have been implemented inside the software:

- permitted domain (the administrator defines the domains from where permission is given to enter the task, the administrator can allow access from a domain only through a single computer with the defined IP);

- ability to define the IP of a barred computer (within permitted domains the administrator can define which computers will not get access to the task);

- automated computer access locking (if the user tries to enter the task for more successive times than permitted by the administrator, this wrong number of entries is interpreted as breaking into the task); 
- defined user name, password and signature (the user must identify the name and password defined by the administrator and signature when performing important operations);

- current session (a session key is created for the user who enters the task, one user cannot run concurrently several sessions);

- entry $\log$ (all attempts to enter and exit the task are recorded);

- action log (it is recorded who entered and when the data was modified, there is also a short-term log record of user's actions during the session);

- encrypted information (the task includes the encryption of key data of facilities, i.e., all the displayable transmissible HTML text information is encoded);

- e-mail address (since the task includes an e-mail-based user interface, also the source e-mail address is used as a protection);

- barred e-mail address (the administrator can define from which e-mail addresses from among those permitted for the user e-mails there is no access to the task).

The protection defined by the environment is as follows:

- restrictions created by the Intranet (since the task operates in the EE Intranet, there is a firewall between the Internet and Intranet);

- protection by NT environment (our Oracle runs on the Windows NT server, and NT has a comprehensive data protection);

- protection by Oracle environment (in order to access data, the user has to enter the Oracle environment that has a comprehensive data protection system);

- code logic (the software code is based on the object-orientation principles).

An administrative data protection procedure has been established that imposes on service personnel the following responsibilities:

- full copies are made of the Oracle database server daily;

- there is disk mirroring in real time (RAID 5);

- in the Oracle Web server a copy is made of the modifications made during a working day, as well as a full copy of the week.

In addition, the Web technology permits us to use secure communication where the transmission channel is also crypted.

\section{PRINCIPLES OF HARDWARE CONFIGURATIONS}

Oracle's Internet computing model is based on a three-tier computing model, in which Oracle Application Server functions as the middle tier or application server tier. In a three-tier model, a middle tier exists between clients and the database server. This middle tier consists of an application server that contains the bulk of the application logic. Clients in this model are thin clients. With this architecture, application logic resides in a single tier and can be maintained easily at one point. The architectural design of the middle tier can also be optimized for server functions since it does not have to house the database. 
When designing the network management software, we proceeded from the premise that the software must be readily expandable and major units must be able to detach themselves for an independent operation of the applications. Therefore a distributed database system was designed. The databases have an identical structure that makes them simple to maintain. Several databases can be run on a single database server. Should the server's capacity begin to drop for one reason or another, some of the databases can be transferred to another server. In order to reduce server loads, each user group has its own Web server, located in a computer, different from the database server. There is a three-layer hierarchy. Users communicate only with the Web server assigned to them. The databases are interconnected by means of Oracle database links (Fig. 6). Additional server was used for computations related to neural networks and equations used in measurements $\left[{ }^{47-49}\right]$.

Another possibility to reduce loads is to use new clustering and caching ideology presented in $\left[{ }^{38,39,50}\right]$.

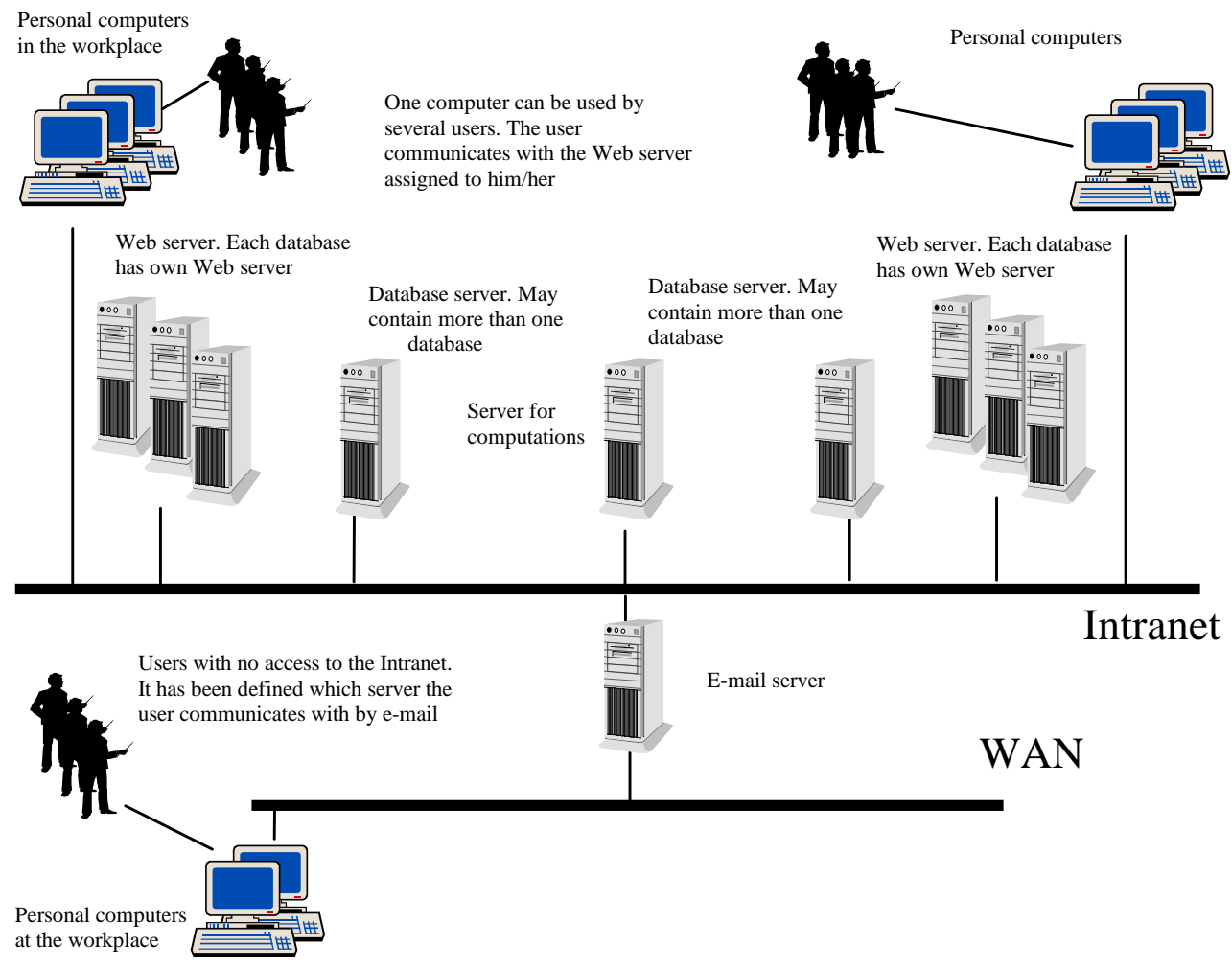

Fig. 6. The principal hardware configuration. 


\section{CONCLUSIONS}

This paper has described the structure of the software for network technical management, the functions of its domains, and development potential. For illustrative purposes, the network management software Event Navigator (ENav), developed at Eesti Energia AS, was used. This software is Web-based, developed by the help of Oracle tools. ENav covers power plants, the transmission network, communication systems, measuring points, telemeasuring, and operational management structures. It is oriented to operational planning and coordination, and to analysis of results, enabling an optimal functioning of the network.

The software developed enables us to describe all such networks where network element administration is involved, and includes the definition, registration, planning, implementation, and work analysis.

In order to manage the operations of network elements, the software uses a mesh structure to link nodes and a tree-shape hierarchy to describe intranode layers. These two structures combined allow us to describe any management structure. To interconnect the network element and management structures, the term "relevance" was used, which defines the functions of the node for a respective element. Thus, each element develops its own management structure.

The team, consisting of four members, with the author as project manager, created ENav during four years.

\section{REFERENCES}

1. MAXIMO. www.mro.com. Accessed 6 Aug 2001.

2. SIEMENS. www.ev.siemens.de/en/powersystemscontrol/. Accessed 30 June 1997.

3. SAP. www.sap.com. Accessed 6 Aug 2001.

4. Landis\&Gyr Utility Services Inc. www. landisgyr.com. Accessed 10 Oct 1997.

5. ABB. www.abb.com. Accessed 6 Aug 2001.

6. HARRIS. www.gepower.com/en_us/. Accessed 6 Aug 2001.

7. FORTUM. www.fortum.com. Accessed 6 Aug 2001.

8. Eesti Energia AS. Invitation for Bids. Procurement of GIS for the National Grid and Electrical Distribution Networks. Tallinn, September, 1998.

9. Geographic Information Systems. http://www.usgs.gov/research/gis/title.html. Accessed 6 Aug 2001.

10. GIS WWW. Resource List. http://www.geo.ed.ac.uk/home/giswww.html. Accessed 6 Aug 2001.

11. Estonian Power System, Tallinn, Estonia, National Dispatch Center for SE Eesti Energia. Vol. 2: SCADA/EMS Functionality, Vol. 3: Appendixes. Harris Energy Control Systems. Melbourne, Florida, 1997, Oct. 15, ref: 8020-49.

12. Estonian Power System, Eesti Energia, Bidding Documents. Procurement of Dispatch Center and Remote Terminal Units. Supply \& Installation. Vol. 2. Prepared by: Eesti Energia, Electrotek Concepts and EPIC Engineering under contract with the United States Trade and Development Agency, 1997, Oct. 14, ref: ME 73050005.

13. Proposal for Procurement of Dispatch Center and Remote Terminal Units. Vol. 2. IVO Power Engineering Ltd, Vantaa, 1997, Oct. 14, ref: PSC/EST-A2-375.

14. Estonian Power System, Eesti Energia, Proposal and Quotation for Supply and Installation of Dispatch Center and Remote Terminal Units. Vols. 1,2. SIEMENS, 1997, Oct. 7, ref: U3452-O-U000-053500. 
15. SINAUT Spectrum System Description. SIEMENS, 1997, Oct. 7, ref: U3452-O-U000-053500.

16. TEKLA, XPOWER. The Network Information Management Solution for Energy Distribution. http://www.tekla.fi/xpower.html. Accessed 6 Aug 2001.

17. Tekla DMS ${ }^{T M}$ Reference Guide, Xpower DMS 6.1. Tekla, Finland, 2000.

18. Acuńa, S. T. and Sosa, M. del V. A culture-centered multilevel software process cycle model. In Proc. World Multiconference on Systemics, Cybernetics and Informatics. 2001, Orlando, Florida, 1, 243-249.

19. Qiu, X. and Wimmer, W. Applying Object-Orientation and Component Technology to Architecture Design of Power System Monitoring. http://icawww2.epf1.ch/ opreiss/ CBSE_Conference2000/papers/SP8.pdf. Accessed 6 Aug 2001.

20. Dugan, R. C. and McDermott, T. E. Design of interfaces for power systems analysis components. In IEEE Power Engineering Society Summer Meeting. Alberta, 1999, 2, 852 857.

21. Liao, Y., Zhao, Q., and Ji, Y. Application of component object model for power system development. In Proc. World Multiconference on Systemics, Cybernetics and Informatics. 2001, Orlando, Florida, 15, 391-396.

22. Mullender, S. Distributed Systems. 2nd ed. Addison-Wesley, Workingham, 1993.

23. Coulouruis, G., Dollimore, J., and Kindberg, T. Distributed Systems: Concepts and Design. 2nd ed. Addison-Wesley, Workingham, 1994.

24. Johnson, R. A. and Hardgrave, B. C. Object-oriented methods: Current practices and attitudes. J. Syst. Softw., 1999, 48, 5-12.

25. Voorhoeve, M. and van der Aalst, W. M. P. Ad-hoc workflow: problems and solutions. In Proc. 8th DEXA Conference on Database and Expert Systems Applications. Toulouse, 1997, 36-41.

26. Lausterer, K. G. IT solutions for power plant management in competitive markets. IEEE Comput. Contr. Eng. J., 2001, 12, 53-62.

27. Schill, A. Distributed application support: Survey and synthesis of existing approach. Inf. Softw. Technol., 1990, 32, 545-558.

28. Aknine, S. and Pinson, S. Agent oriented conceptual modeling of parallel workflow systems. In Lecture Notes in Computer Science, No. 1611. Springer-Verlag, Berlin, 1999, 500-509.

29. Bussler, C. A systematic approach for informal communication during workflow execution. In Lecture Notes in Computer Science, No. 1777. Springer-Verlag, Berlin, 2000, 388-392.

30. Allen, L., Fernandez, G., Kane, K., Leblang, D., Minard, D., and Posner, J. Clearcase multisite: Supporting geographically-distributed software development. In Software Configuration Management (Estublier, J., ed.). Lecture Notes in Computer Science, No. 1005. SpringerVerlag, Berlin, 1994, 194-214.

31. Alsono, G., Mohan, C., and Kamath, U. Handling disconnected clients in a workflow management system. In Proc. 3rd International Conference on Cooperative Information Systems CoopIS-95. Vienna, 1995, 99-110.

32. Schneider, G., Maus, H., Dietel, C., Scheller-Houy, A., and Schweitzer, J. First steps from workflow management systems towards enterpriseware. In Proc. Workshop on Coordinating Work Processes. Universität Kaiserslautern, 1996.

33. Cegrell, T. Power System Control Technology. Prentice-Hall, London, 1986.

34. Uchôa, E. M. A., Melo, R. N., and Heros, F. W. A framework for heterogeneous database systems integration. In Lecture Notes in Computer Science, No. 1677. Springer-Verlag, Berlin, 1999, 656-667.

35. Power Technologies, Inc. www.pti-us.com. Accessed 6 Aug 2001.

36. Fischer, G. Domain-oriented design environments: Supporting individual and social creativity. In Computational Models of Creative Design (Gero, J. and Mahe, M. L., eds.). Key Centre of Design Computing and Cognition, Sydney, 1999, 4, 83-111.

37. Simone, C. and Ariadne, M. D. Supporting coordination through a flexible use of the knowledge on work processes. J. Univers. Computer Sci., 1997, 3, 865-898.

38. Cluster and Parallel Storage Technology. http://www.oracle.com/ebusinessnetwork/openworld/ emea/shows.html. Accessed 6 Aug 2001. 
39. Ellison, L. The Launch of Oracle9i - Software Powers the Internet. http://www.oracle.com/ ebusinessnetwork/. Accessed 6 Aug 2001.

40. Singh, J. The importance of information flow within the supply-chain. Logist. Inf. Manage., 1997, 9, 28-30.

41. Santos, J., Faria, L., Ramos, C., Vale, Z. A., and Marques, A. Verification of knowledge-based systems for power system control centres. In Lecture Notes in Computer Science, No. 1611. Springer-Verlag, Berlin, 1999, 316-325.

42. Van der Aalst, W. M. P. Flexible workflow management systems: An approach based on generic process models. In Lecture Notes in Computer Science, No. 1677. Springer-Verlag, Berlin, 1999, 186-195.

43. Akao, Y. Quality Function Deployment: Integrating Customer Requirements into Product Design. Productivity Press, Cambridge, 1990.

44. Busbach, U. Distributed work management: An application area for mobile computing. In Proc. Hawaii International Conference on Systems Sciences. Maui, Hawaii, 1995. IEEE Computer Soc. Press, 1995, 4, 34-41.

45. Calabrese, G. Managing information in product development. Logist. Inf. Manage., 1999, 12, 439-450.

46. Kangilaski, T. Fault prediction in power network. In The 7th Biennal Conference on Electronics and Microsystems Technology. Tallinn, 2000, 289-292.

47. Busler, C. and Jablonski, S. Scalability and extensibility through modularity: Architecture of the mobile workflow management system. In Proc. 5th Workshop on Information Technologies and Systems WITS'95. Amsterdam, 1995, 98-107.

48. Worah, D. and Sheth, A. P. Transactions in transactional workflows. In Advanced Transaction Models and Architectures (Jajodia, S. and Kerschberg, L., eds.). Kluwer, 1997, 3-33.

49. Dittrich, K., Gotthard, W., and Lockemann, P. Damokles, a database system for engineering environments. In Proc. International Workshop on Advanced Programming Environment (Conradi, R., Didriksen, T. M., and Wanvik, D. H., eds.). Trondheim, 1986. SpringerVerlag, 1986, 244 of LNCS, 353-371.

50. KeyNotes. http://www.oracle.com/ebusinessnetwork/openworld/emea/keynotes.html. Accessed 6 Aug 2001.

\section{Suurte ülekandesüsteemide tehnilisest haldamisest}

\section{Taivo Kangilaski}

On vaadeldud suurte ülekandevõrkude kirjeldamist tarkvaras ning käsitletud üksikuid süsteemi osi ja nende funktsioone, mida võrguhaldustarkvara peab võimaldama juhtida. Tarkvara ülesanne on tagada erinevate üksuste katkematu koostöö, tegevuse analüüs ja arengu planeerimine ning kindlustada võrgu kui terviku optimaalsele lähedane funktsioneerimine. Probleemi on selgitatud Eesti Energia ASi tarkvara "Sündmuste registraator" näitel. 